\title{
Y-Maze Behavior After an Analog of ACTH 4-9, Evidence for an Attentional Alteration
}

\author{
R. J. Katz and R. Chudler \\ Mental Health Research Institute, Department of Psychiatry, University of Michigan Medical Center, Ann Arbor, Michigan 48109, USA
}

\begin{abstract}
Adult, male, Swiss-Webster mice were injected with either control solution or various doses of a long-acting analog of ACTH 4-9. The drug produced significant alterations in performance in an equiangular Y-maze. In comparison with control performance, both 25 and $50 \mu \mathrm{g} / \mathrm{kg}$ of drug produced a significant increase in repeated two-arm entries. This response pattern is consistent with the hypothesis that the drug produced a focusing of attention.
\end{abstract}

Key words: ACTH 4-9 - Attention - Y-maze performance

Fragments of adrenocorticotropic hormone (ACTH) without intrinsic corticotropic activity may manifest neurotropic activity. These neurotropic actions may include effects upon learning and extinction, attention (see Van Riezen et al. 1977; Walker and Sandman 1979 for recent summaries), grooming, and analgesia (Gispen et al. 1975, 1976). Heretofore the attentional theory of neuropeptide activity has been supported by physiological measures of arousal (e.g., Sandman et al. 1977 ) and studies involving various forms of dimensional shifts in learning tasks (e.g., Sandman et al. 1973). In the latter, enhanced reversal learning and impaired extradimensional shifting have been taken as evidence for peptide facilitation of attention.

A less complex, but potentially useful attentional measure is initial performance in a Y-maze. Mice exposed to an equiangular three-arm maze typically show various combinations of response perseveration and alternation. Three-arm entries represent response alternation and are consistent with an influence of motor bias or stereotypy (e.g., Kokkinidis and Anisman 1977, 1978). Repeated two-arm entries on the

Offprint requests to: $\mathrm{R}$. J. Katz other hand demand complex successive reversals of motor responses and may reflect non-motor factors such as an attentional bias or sensory perseveration (op.cit.). Drugs affecting attentional processes typically increase the proportion of two-arm entries at the expense of response perseveration (Kokkinidis and Anisman 1977, 1978). The present design utilized $Y$-maze performance to examine whether the neuropeptide ORG 2766, an analog of ACTH 4-9, would influence attention in a design in which learning was probably not directly involved. Our findings are consistent with the presence of an attentional effect for the compound.

\section{Materials and Methods}

Adult, male, Swiss-Webster mice $(N=42 ; 25-30$ g each, Charles River Farms) were group housed six per cage with food (Teklad $4.0 \%$ fat rodent diet S-0836) and tap water continuously available, and $12 \mathrm{~h}$ day-night cycles (lights on $=7$ a.m. $-7 \mathrm{p} . \mathrm{m}$.).

All testing was carried out from 3 p.m. -6 p.m. Mice were individually removed from housing and injected IP $1 \mathrm{ml} / 0.1 \mathrm{~kg}$ with one of three doses $(25,50,100 \mu \mathrm{g} / \mathrm{kg})$ of ORG 2766 [H-Met $\left(\mathrm{O}_{2}\right)$-Glu-His-Phe-D-Lys-Phe-OH] in $0.9 \%$ sodium chloride vehicle. Testing began $15 \mathrm{~min}$ later. The subject was removed from a $28.5 \times 17.5 \times 12.5$ Plexiglas holding cage and placed in an equiangular three-arm maze for a single 15 -min observation period. Dimensions of individual maze arms were $17.5 \times 6.5 \times 7.5 \mathrm{~cm}$. The maze was washed thoroughly with tap water between tests. Air circulation equipment in continuous operation provided masking noise of $40 \mathrm{~dB}$.

Performance was assessed as proportion of alternation responses per total responses. This measure has been described in detail by Kokkinidis and Anisman (1977, 1978). Briefly, alternation responses (consecutive three-arm entries) were divided by total arm entries (alternations plus perseveration responses) to yield a net score between 0.0 and 1.0 . Statistical analysis was by univariate analysis of variance with Sheffé limits for post-hoc comparisons (Dixon and Massey 1969).

\section{Results}

Data from vehicle-injected mice indicated a predominant pattern of response bias (i.e., three-arm entries), 
Table 1. Effects of Org 2766 on Y-maze performance in the mouse. Analysis of variance based upon Dixon and Massey (1969)

\begin{tabular}{lrl}
$\begin{array}{l}\text { ORG 2766 } \\
\mu g / k g\end{array}$ & $N$ & $\begin{array}{l}\text { Proportion of alternations in } 15 \mathrm{~min} \\
(x \pm \mathrm{SEM})\end{array}$ \\
\hline Control & 19 & $0.67 \pm 0.01$ \\
25 & 9 & $0.62 \pm 0.03^{\mathrm{a}}$ \\
50 & 9 & $0.60 \pm 0.02^{\mathrm{a}}$ \\
100 & 5 & $0.73 \pm 0.04$
\end{tabular}

a Differs from control performance $P<0.05$ (Sheffe procedure) $F$ ratios for 25 and $50 \mu \mathrm{g} / \mathrm{kg}$ vs. control are $7.2,4.6, P<0.01,0.001$ all other groups are equivalent

and this was reduced significantly by low and intermediate dose of peptide (Table 1).

It might be questioned if these results reffected an underlying non-specific behavioral activation or depression. Since the data are ratios and therefore independent of absolute activity this seems unlikely. However, to test further whether these results reflected some change in activity level, five correlations of total arm entries by proportion of alternations were calculated (one for each cell, one for all subjects regardless of treatment). Regression coefficients of total activity upon proportional alternations for control, the three doses in increasing order, and total subjects were 0.20 , $0.18,0.11,-0.04$, and 0.19 . Fisher transformations to $Z$ scores indicated $Z$ ratios of $0.8,0.5,0.3,0.1$ and 1.3 respectively. In all cases these results are below levels reliably different from chance.

\section{Discussion}

It should be noted that the dose response curve was not monotonic. Bitonic responses have also been noted for other peptides (Frederickson et al. 1978; Krivoy et al. 1979). The findings may reflect indirect "neuromodulatory" process similar to those described by Krivoy et al. (1979). As previously noted the predominance of three-arm entries may also reflect peptide induced motor bias. Finally, the findings might indicate an attentional disorganization, being even higher than the control mean, although not reliably so. Such processes have been described by Meldman (1970), who notes that attention may be ordered upon a continuum in which the highest extreme involves disorganized behaviors. Once an attentional optimum is exceeded performance may be predicted to decline.
Whether or not this last explanation in fact accounts for the present results, overall, the intermediate dose effects are consistent with the experimental hypothesis, and may be taken to support and extend prior studies on neuropeptides and attention. Future studies might outline further localized central injections (Kokkinidis and Anisman 1977) to further test the attentional nature of the $\mathrm{Y}$-maze effect.

Acknowledgements. The experiment was carried out by the second author for course credit as an independent undergraduate project in biology. We acknowledge the statistical advice of Robert Shea. Organon 2766 was generously donated by Organon, Oss, Netherlands.

\section{References}

Dixon WJ, Massey FJ (1969) Introduction to statistical analysis, 3rd edn. McGraw Hill, New York

Frederickson RCA, Burgis V., Harrell CE, Edwards JD (1978) Dual actions of substance $P$ on nociception: possible role of endogenous opioids. Science 199, 1359-1362

Gispen WH, Buitelaar J, Wiegant VM, Terenius L, DeWied D (1976) Interaction between ACTH fragments, brain opiate receptors, and morphine induced analgesia. Eur J Pharmacol 39:393-398

Gispen WJ, Wiegant VM, Greven HM, DeWied D (1975) The induction of excessive grooming in the rat by intraventriculat application of peptides derived from ACTH, structure activity studies. Life Sci 17:645-652

Kokkinidis L, Anisman H (1977) Perseveration and rotational behavior elicited by $d$-amphetamine in a Y-maze exploratory task: differential effects of intraperitoneal and unilateral intraventricular injection. Psychopharmacology 52:123-128

Kokkinidis L, Anisman L (1978) Abatement of stimulus perseveration following repeated $d$-amphetamine treatment: absence of behaviorally augmented tolerance. Pharmacol Biochem Behav 8:557-563

Krivoy WA, Couch JR, Henry JL, Stewart JM (1979) Synaptic modulation by substance P. Fed Proc 38:2344-2347

Meldman MJ (1970) Diseases of attention and perception. Pergamon, New York

Sandman CA, Alexander WD, Kastin AJ (1973) Neuroendocrine influences on visual discrimination and reversal learning in albino and hooded rats. Physiol Behav 11:613-617

Sandman CA, George J, McCanne TR, Nolan JD, Kaswan J, Kastin AJ (1977) MSH/ACTH 4-10 influences behavioral and physiological measures of attention. J Clin Endocrinol Metab $44: 884-891$

VanRiezen HH, Rigter H, Dewied D (1977) Possible significance of ACTH fragments for human mental performance. Behav Biol $20: 311-324$

Walker B, Sandman CA (1979) Influence of an analog of the neuropeptide ACTH 4-9 on mentally retarded adults. Am J Ment Defic 83:346-352

Received February 26, 1980; Final version May 28, 1980 